\title{
Implications of the Flipped Classroom on College English Teaching under the Background of Reform
}

\author{
Wei Liu \\ School of Foreign Languages, Jilin Agricultural University, ChangChun 130118, China \\ 29897259@qq.com
}

Key words: Flipped Classroom; College English Teaching; Reform

\begin{abstract}
College English as a public foundation course in college, involving a wide range of students, has a high impact on college students. The continuous improvement of College English teaching is the need to comprehensively enhance the quality of higher education. Over the years, facing the reform of College English teaching and its problems, college English teachers and researchers have been in the search for a new model to effectively improve teaching effect,and flipped classroom is undoubtedly a feasible attempt. This article starts with the problems existing in the College English Teaching under the background of reform, combined with the characteristics and theoretical basis of the flipped classroom, and discusses implications of the flipped classroom teaching mode on College English teaching.
\end{abstract}

\section{Introduction}

English, one of the most widely used languages in the world, has become an important tool in international communication in science and technology and cultural exchanges. College English as a public foundation course in college, involving a wide range of students, has a high impact on college students. The continuous improvement of College English teaching is the need to comprehensively enhance the quality of higher education. Over the years, facing the reform of College English teaching and its problems, college English teachers and researchers have been in the search for a new model to effectively improve teaching effect,and flipped classroom is undoubtedly a feasible attempt.

\section{Problems existing in College English Teaching}

Examination-oriented Education

Although quality education has been put forward for many years, most of the university education in China, especially in the College English teaching is still examination oriented. Over the years, the mode of the exam oriented education makes college English teaching not cultivate students' interest in learning English and learning ability of teaching and learning, but prepare for and cope with a variety of teaching and examination. The evaluation standards of teaching are not to improve the practical ability of students, but pass rate and excellence rate in a variety of exams. In this context, the method of language teaching is excessive assignments tactic, and the students do well in exams, but in the real communication with native speakers, students appears to be very reserved and unprepared. Students' comprehensive English ability, especially basic skills such as listening and speaking, is difficult to greatly improve, resulting in the fact that quality education is very difficult to achieve.

Teaching Model Being Traditional

For a long time, the College English teaching model in China has been traditional and unitary.The classroom is always teacher-centered, and students are often in a passive acceptance to the transfer of knowledge. There is no opportunity to participate in the classroom, which leads to the students loss of their in, the loss of learning enthusiasm and initiative in College English learning and also lead to the "dumb English" phenomenon. Over the years, the teacher-centered grammar translation method has occupied our college English teaching classroom as the absolute 
protagonist, and even today, this phenomenon is not greatly changed. Many college English teachers admitted their own teaching method is still "the grammar translation method". They explain that they also know the currently fashionable teaching method, but due to various reasons, such as the actual level of the students, teachers' language skills, limited time, the number of students, exam pressure and so on, teachers and students find out in the end "the grammar translation method more realistic" .

The Construction of Teaching Materials Lagging behind

From the point of view of teaching materials, most of them are relatively simple and the most important is that what students learned in colleges English class is a large part of the repetition in their middle school, which is unattractive for the students who are good at English. In recent years, although domestic publishing presses compete to write and publish some university English textbooks and other instructional materials, these materials lag in the development of the times since its publication, coupled with some topics which themselves are difficult to aroused interest in modern college students. This will cause students' neglect of English study, and even lose interest in the subject.

In addition, the arrival of a new round of the reform of College English teaching makes the university English teaching facilities, class hour arrangement, teaching environment in many colleges and universities not completely meet actual demand. Facing these problems, college English teachers and researchers have been in the search for a new model to effectively improve teaching effect,and flipped classroom is undoubtedly a feasible attempt.

\section{The Flipped Classroom and Its Implications to College English Teaching}

In 2011, Salman Khan in his TED (Technology Entertainment Design, a private non-profit organization) conference presentation "Using video to recreate education" mentioned: many students could watch the the mathematics teaching video of Khan Academy at home in the evening, and the next day they went back to the classroom to do homework,and would consult their teacher and classmates when having questions. This is the opposite to traditional classroom in which "teachers give classes in the day in the classroom and students do homework at home in the evening", which is called the "flipped classroom". Since then, the "flipped classroom" has become educators' focus of their attention, and was evaluated as a major technological change in classroom teaching in 2011 by The Globe and Mail in Canada.

The Characteristics of the Flipped Classroom

Researchers found that Khan Academy offers numerous instructional videos for teaching so that students can watch videos according to their own time, at their own pace at home,and teachers can no longer use classroom time to teach the new curriculum and use precious class time for answering questions for students. That means the homework part moves to the classroom and students only need to complete the basic learning at home. There are mainly two characteristics to solve the problems in traditional teaching model:

First, it can provide more knowledge and information that the traditional classroom teaching can't give because of the time limitation. In the traditional classroom, there are only $40 \sim 45$ minutes and even using all the class time, teachers can't explain all the details. In such way, students often accept knowledge passively which can not attract the attention of both good and poor students. And in the flipped classroom, students can enjoy their learning at their pace and time and abundant knowledge.

Second, students can find their weaknesses at home and consult their teachers and classmates in the classroom to solve their problems timely. In the traditional way, students only listen to their teachers in the classroom and go home to finish the homework. When they encounter problems, no one can help them which naturally will make students frustrated, and a lot of homework deprive the students of their valuable time to rest. This will lead to the fact that learning becomes the burden of students. In the flipped classroom, students with problems can have chances to ask for help from their teachers and classmates to solve their problems which can benefit them so much.

The Theoretical basis of the Flipped Classroom 
In 2013, Dr. Patrick McKnight of George Mason University, Dr. NooraHamdan of Pearson Education Development Center and Dr. Kari M.Arfstrom of the Flipped learning network released "Flipped classroom white paper" based on research center data summary the Flipped learning network having summarized the recent worldwide research and experiments of the flipped classroom model design, which stated that no section of the flipped classroom is exactly the same, but the success of the flipped classroom design depends on many factors, so they put forward four pillars, namely: flexible flipped classroom learning environment, the change of learning culture, the intentional content carefully planned and professional teachers.

(1) The flexible learning environment

A variety of teaching modes can be used in the flipped classroom, including group cooperation, thinking, reporting and mutual evaluation. The flexible environment means that students can choose the time and place of study, whether in the classroom or on campus, or on the way to school; In addition, teachers of the flipped classroom teaching, often hold flexible attitude towards the student's learning progress, and use flexible ways to evaluate students learning and development, which are beneficial to both teachers and students.

(2) The change of learning culture

In the traditional teaching mode, the classroom is teacher-centered and the teacher is the "leader", the main source of teaching knowledge and can't be challenged. However, in the flipped classroom, the main task of the classroom turns to learning from teaching. Before entering the classroom, students have learned some basic knowledge and in the classroom they can learn the content for more in-depth discussions, research and creative learning. Compared to the traditional passive learning, students are more willing to accept group work, discussion in the flipped classroom,and teachers in the process can give help to enable students to better understand the knowledge.

(3) Intentional content carefully planned

Teachers designing the flipped classroom, need to think about how to design preclass activities, classroom teaching, after-school evaluation, etc., how to use teaching content to help students to improve the understanding of the concept, to master skills proficiency. Therefore, teachers need to consider again and again what should be explained in the classroom, what should be learned by students' autonomous learning, and what to discuss in group in the classroom. The teaching content carefully designed can help teachers make maximum use of class time, and according to the characteristics of different disciplines and different learners, use a variety of teaching methods, to design each section "flipped classroom”comprehensively.

(4) Professional teachers

Compared with the traditional classroom, the teacher's role changes, which is no longer the former one. At the same time, the flipped classroom is demanding for teaching, because teachers not only need to grasp the teaching processors but also master the skills to prepare the videos , e books and other materials which demands higher professional knowledge and skills and also means teachers should better equip themselves with continuous learning and study.

Implications and Reference to the College English Teaching

(1) The feasibility of applying the flipped classroom teaching into College English Teaching

Recently more and more attention has been to the cultivation of students' comprehensive language ability, and the classroom is the main position to train students, and a key factor to influence the learning effect of students. The development of social economy, requires students to master not only the traditional reading and writing skills, but also should have strong ability of communication and teamwork. But there is a big gap between China's College English teaching and social demands, so the reform of classroom teaching is needed to make up for that.

Flipped classroom can make college English teaching return to the cultivation of students' ability. The flipped classroom will shift the ordinary classroom teaching to the extracurricular. Students can become active learning participants through training, discussion,and cooperative team work which can help students improve their comprehensive language ability directly in the classroom.

(2) Several problems in the flipped classroom applied to College English Teaching First, pay attention to the reconstruction of classroom teaching. The flipped classroom should not 
simply move contents of the class to outside of the classroom, but do a completely new design to the traditional classroom including teaching contents, teaching methods, teaching tasks and the like.

Second, focus on the design of videos before class. In the flipped classroom, students learn knowledge in advance by videos teachers provide and therefore, the design of videos should be able to attract the students attention, and pay attention to the timely feedback.

Third, consider the applicability of the course. Not all courses are suitable for the use of the flipped classroom teaching model, in particular, courses which are difficult to self-study for students , and they are not necessarily suitable for the flipped classroom model.

\section{Conclusion}

In summary, the flipped classroom has a positive inspiration to College English teaching under the background of reform of, but there exists some problems in implementing the flipped classroom. For instance, students often do not take the initiative to collect extra resources, at the same time due to the limited energy of teachers, they can not take into account the learning situation of every member in the classroom, and even sometimes teachers can solve all the problems timely, thus impeding the effective implementation of the flipped classroom.

\section{References}

[1] Wang Shou-ren, Wang Hai-xiao Survey of College English Teaching in China and Reform and Development of College English Teaching [J]. Chinese Journal of foreign languages 2011(9) 4-11

[2] Cai Ji-gang, Liao Lei-zhao. ELE or ESP, on the Direction of Development of College English Teaching in China [J]. Computer-assisted Foreign Language Education, 2010 (5): 2026.

[3] Wang Dan, Liu Jian-zhi. Review of research and Practice on flipped classroom at home and abroad [J]. Contemporary Educational Theory and Practice, 2014, (2): 68-71.

[4] Zhang Jin-lei, Wang Ying, Zhang Bao-hui. Research on the Teaching Mode of Flipped Classroom [J]. Journal of Distance Education, 2012, (4): 46 51 